Article

\title{
Application of Adzuki Bean Starch in Antioxidant Films Containing Cocoa Nibs Extract
}

\author{
Sujin Kim, Su-Kyoung Baek, Eunjeong Go and Kyung Bin Song * \\ Department of Food Science and Technology, Chungnam National University, Daejeon 34134, Korea; \\ pppink32@gmail.com (S.K.); sukyoungb@naver.com (S.-K.B.); ko8546882@naver.com (E.G.) \\ * Correspondence: kbsong@cnu.ac.kr; Tel.: +82-42-821-6723
}

Received: 2 October 2018; Accepted: 30 October 2018; Published: 31 October 2018

\begin{abstract}
In this study, starch extracted from adzuki bean (ABS) was used as a biodegradable film source. In addition, to develop a new antioxidant film, various amounts of cocoa nibs extract (CNE, $0.3 \%, 0.7 \%$, and $1 \%$ ) were incorporated. With the addition of CNE, the elongation at break of the ABS films increased and the tensile strength decreased. The ABS films with CNE showed increased 2,2'-azino-bis-3-ethylbenzthiazoline-6-sulphonic acid (ABTS) and 1,1-diphenyl-2-picrylhydrazyl (DPPH) scavenging activities with increasing amounts of CNE. In particular, the ABTS and DPPH radical scavenging activities of the ABS films containing 1\% CNE were $100 \%$ and $94.9 \%$, respectively. Furthermore, decomposition of the films was observed after 28 days of biodegradation. Thus, ABS films containing CNE can be applied as a new active packaging material.
\end{abstract}

Keywords: adzuki bean; antioxidant activity; biodegradable films; cocoa nibs extract

\section{Introduction}

The use of synthetic polymers in the food packaging industry has increased because of their convenience. However, synthetic polymers cause environmental problems, as they are difficult to decompose naturally. Thus, interest in eco-friendly biopolymers as a substitute for synthetic polymers has increased [1]. Starch is widely studied as a base material for biodegradable films because it is one of the most abundant land resources and has good film-forming ability and biodegradability [2]. Among starches, cassava, corn, and potato have been widely used, but few studies have been conducted to develop films based on under-utilized starch sources.

Adzuki bean (Vigna angularis) is a traditional legume that has been cultivated throughout East Asia for a long time [3] and is the second most economically important legume in Japan [4]. Adzuki bean contains approximately $60 \%$ starch in its composition, and the amylose content of adzuki bean starch (ABS) is estimated at around $20 \%$ to $30 \%$ [3,5]. Despite its high starch and amylose content, the usage of ABS in the food industry has been limited and ABS has not been reported as a film base material.

Biodegradable films have been applied in various active and smart packaging systems [6]. Among them, active packaging can be developed by adding active materials with antioxidant activity. The incorporation of antioxidants in the films has advantages over direct addition to foods because the antioxidants can be gradually released into packaged food, resulting in extension of shelf life by delaying lipid oxidation in the foods. Antioxidants can be obtained synthetically or naturally. However, as consumer interest in health has increased, natural antioxidants have received more attention than synthetic preservatives. Many studies have focused on natural antioxidants, such as yerba mate, rosemary, and tea extracts [7-9].

Recently, there has been growing interest in polyphenols due to their health benefits, including antioxidant, anti-inflammatory, and anti-atherogenic effects [10]. Cocoa nibs, which are derived from Theobroma cacao L., have been extensively studied. In particular, cocoa nibs extract (CNE) is 
a good source of phenolic compounds, principally flavan-3-ol compounds such as catechin and epicatechin $[10,11]$. Among natural antioxidants, CNE exhibits higher antioxidant activity $(253.9 \mu \mathrm{mol}$ of TE/g) than blackberry extract (55.7 $\mu \mathrm{mol}$ of TE/g) or cranberry extract $(18.5 \mu \mathrm{mol}$ of TE/g [12,13]. However, at present there are no reports on biodegradable films containing CNE as a natural antioxidant. Therefore, the present study aimed to develop and characterize antioxidant starch films from $\mathrm{ABS}$ and $\mathrm{CNE}$, which have not been applied in the food packaging industry.

\section{Materials and Methods}

\subsection{Materials}

Adzuki bean (Cheonaeji, Incheon, Korea), sorbitol, gallic acid, and epicatechin (Sigma-Aldrich Co., St. Louis, MO, USA) were used in this study. Cocoa nibs were obtained from Gilim Co., Ltd. (Gwangju, Korea).

\subsection{Extraction of $A B S$}

ABS was prepared according to the method described by Hoover et al. [5] with minor modifications. Adzuki bean powder and $0.3 \% \mathrm{NaOH}$ solution $(1: 5, w / v)$ were mixed and stirred $\left(4{ }^{\circ} \mathrm{C}, 24 \mathrm{~h}\right)$. The solution was then passed through a 200-mesh sieve and centrifuged at $3800 \times \mathrm{g}$ for $10 \mathrm{~min}$. Afterwards, the pellet was mixed in distilled water (DW) and neutralized with $1 \mathrm{~N} \mathrm{HCl}$ solution. The slurry was kept at $4{ }^{\circ} \mathrm{C}$ for $1 \mathrm{~h}$ and the pellet was dried in a drying oven (DDO-102, Daeil Engineering Co., Seoul, Korea) at $50{ }^{\circ} \mathrm{C}$ for $24 \mathrm{~h}$. Starch yield was calculated based on adzuki bean flour (dry basis). The yield of the starch was $40 \%$, which was higher than that reported in the literature [5].

\subsection{Extraction of CNE}

CNE was extracted from cocoa nibs as described by Mazor Jolić et al. [12] with minor modifications. Cocoa nibs $(10 \mathrm{~g})$ and $70 \%$ ethanol $(100 \mathrm{~mL})$ were mixed and stirred at $25^{\circ} \mathrm{C}$ for $5 \mathrm{~h}$. Whatman filter paper No. 2 was then used for filtration, and the filtrate was concentrated with a vacuum evaporator and dried using a freeze-drier (FD5508, Ilshin Lab Co., Yangju, Korea).

\subsection{Amylose Content of ABS}

The amylose content of ABS was determined [14]. ABS powder $(100 \mathrm{mg}), 95 \%$ ethanol $(1 \mathrm{~mL})$, and $1 \mathrm{~N} \mathrm{NaOH}$ solution $(9 \mathrm{~mL})$ were mixed and heated in a water bath at $80^{\circ} \mathrm{C}$ for $10 \mathrm{~min}$. After cooling down for $15 \mathrm{~min}$, DW was added and the solution $(5 \mathrm{~mL}), 1 \mathrm{~N}$ acetic acid $(1 \mathrm{~mL})$, and I2-KI solution $\left(2 \mathrm{~mL}\right.$ ) were mixed and topped with DW to $100 \mathrm{~mL}$. The mixture was kept at $25^{\circ} \mathrm{C}$ for $20 \mathrm{~min}$ and the absorbance was measured at $620 \mathrm{~nm}$ using a spectrophotometer (UV-2450, Shimadzu Corporation, Kyoto, Japan).

\subsection{CNE Analysis}

The CNE composition was analyzed using a high-performance liquid chromatography (HPLC) system (Waters Corporation, Milford, MA, USA) using an Xbridge ${ }^{\mathrm{TM}} \mathrm{C} 18$ column $(4.6 \mathrm{~mm} \times 50 \mathrm{~mm}$, Waters Corporation, Milford, MA, USA) according to the method described by Schinella et al. (2010). Prior to injection into the column, CNE and standard chemical (epicatechin) were dissolved in methanol and passed through a polyvinylidene fluoride filter $\left(0.45 \mu \mathrm{m}\right.$, Whatman ${ }^{\mathrm{TM}}$, Clifton, NJ, USA).

\subsection{Preparation of ABS Films Containing CNE}

To prepare the ABS films containing CNE, ABS (2.5\%) and sorbitol $(0.4 \mathrm{~g} / \mathrm{g}$ ABS) were first dispersed in DW and stirred at $80{ }^{\circ} \mathrm{C}$ for $20 \mathrm{~min}$. Various amounts $(0.3 \%, 0.7 \%$, and $1 \%$ ) of CNE were then added to the film-forming solution and sonicated for $5 \mathrm{~min}$. The filtered film solution $(30 \mathrm{~mL})$ 
was uniformly spread onto glass plates and dried on a clean bench at $25^{\circ} \mathrm{C}$ for $15 \mathrm{~h}$. The control film was prepared using ABS and sorbitol only without the addition of CNE.

\subsection{Physical Properties}

The physical properties of the ABS films were examined using a Testometric machine (250-2.5 CT, Testometric Co., Lancashire, UK). The water vapor permeability (WVP), water solubility (WS), and moisture content (MC) of the ABS films were measured as described by Yang et al. [15]. Five replications were recorded independently.

\subsection{Color Measurement and Ultraviolet (UV)-Visible Light Transmittance}

To analyze the color of the ABS films, a colorimeter (CR-400, Minolta, Tokyo, Japan) was used. According to the CIELAB color scale, the $L^{*}$ (lightness), $a^{*}$ (redness), and $b$ * (yellowness) values were examined. In addition, the opacity of the ABS films was determined using a spectrophotometer (UV-2450, Shimadzu Corporation, Kyoto, Japan) [16]. To analyze the UV-visible light transmittance of the ABS films in the range of 200 to $800 \mathrm{~nm}$, a spectrophotometer (UV-2450, Shimadzu Corporation) was used.

\subsection{Total Phenolic Content (TPC)}

The TPC of the ABS films was estimated according to the method described by Adilah et al. [17], and gallic acid was used as a standard.

\subsection{Antioxidant Activity}

Assays of 2,2'-azino-bis-3-ethylbenzthiazoline-6-sulphonic acid (ABTS) and 1,1-diphenyl2-picrylhydrazyl (DPPH) radical scavenging were performed to examine the antioxidant activity of ABS films containing CNE [16].

\subsection{Attenuated Total Reflectance-Fourier Transformation Infrared (ATR-FTIR) Spectroscopy}

An FT-IR spectrophotometer (VERTEX 80v, Bruker Optics, Billerica, MA, USA) was used to obtain the ATR-FTIR spectra of ABS films containing CNE in the wavenumber range of 4000 to $400 \mathrm{~cm}^{-1}$.

\subsection{Differential Scanning Calorimetry (DSC) and Thermogravimetric Analysis (TGA)}

DSC and TGA were conducted using a differential scanning calorimeter (DSC1; Mettler Toledo, Columbus, $\mathrm{OH}, \mathrm{USA}$ ) at a rate of $10^{\circ} \mathrm{C} / \mathrm{min}$. Each sample was scanned from 0 to $200{ }^{\circ} \mathrm{C}$ for DSC and heated from 25 to $700{ }^{\circ} \mathrm{C}$ for TGA.

\subsection{Biodegradation Test}

The biodegradability of the ABS films was evaluated according to the method described by Assis et al. [18] with minor modifications. Each film $(2 \mathrm{~cm} \times 2 \mathrm{~cm})$ was weighed and buried in the vegetable compost inside a plastic tray $(15 \mathrm{~cm} \times 25 \mathrm{~cm})$. The trays were kept at $25^{\circ} \mathrm{C}$ and $60 \%$ relative humidity for 28 days. After 4, 7, 14, 21, and 28 days, the films buried in the soil were weighed.

\subsection{Statistical Analysis}

SAS software (SAS Institute Inc., Cary, NC, USA) was used to evaluate the experimental results. Statistically significant difference was determined at $p<0.05$. All values are presented as mean \pm standard deviation. Each experiment was replicated at least three times. 


\section{Results and Discussion}

\subsection{Starch Yield and Amylose Content}

The yield of the ABS was 40\%, which was higher than that reported in the literature. According to the report by Hoover et al. [5], the ABS yield was $21.5 \%$. The variation of starch yield could be attributed to a different cultivar and physiological state of the seed [5].

The amylose content in starch is important because it can affect the chemical properties of starch and can determine its application [19]. Particularly, for starch-based films, the amylose-amylopectin ratio affects the physical properties of the films because the starch network and gel properties of starch-based polymers are altered [20]. In general, starch with high amylose content renders good physical properties in the starch films. Nogueira et al. [19] reported that amylose content was a determinant of the physical properties of arrowroot starch films. In the present study, the amylose content of ABS was $22.1 \%$, which is similar to a previously reported value [5].

\subsection{HPLC Analysis of CNE}

CNE contains a considerable amount of epicatechin, which has strong antioxidant activity $[11,21]$. Epicatechin is a major component of the CNE prepared in this study (Figure 1). Thus, the antioxidant capacity of CNE is mainly due to epicatechin. Similarly, Schinella et al. [10] reported the high antioxidant activity of CNE with epicatechin as the major component, assessed using HPLC.

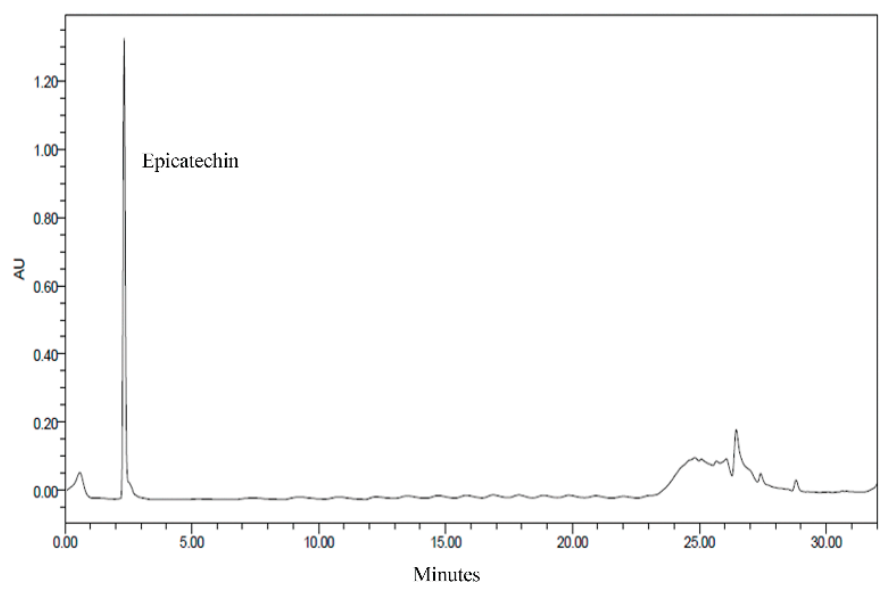

Figure 1. High-performance liquid chromatography (HPLC) chromatogram of cocoa nibs extract.

\subsection{Physical Properties of ABS Films Containing CNE}

The thickness, tensile strength (TS), elongation at break (E), and WVP of ABS films containing CNE are presented in Table 1. The incorporation of CNE decreased the rigidity of the ABS films and increased their flexibility. In particular, the ABS film without CNE exhibited a TS of 30.59 MPa, whereas those of the films incorporated with various amounts of CNE $(0.3 \%, 0.7 \%$, and $1 \%)$ decreased to $27.74,25.50$, and $18.58 \mathrm{MPa}$, respectively. In contrast, the $E$ values of the ABS films increased from $10.11 \%$ to $27.80 \%$ when the amount of CNE increased from $0 \%$ to $1 \%$. These results suggest that the incorporation of CNE into the ABS films led to structural changes, resulting in a decrease in intermolecular interactions among starch molecules. These findings are consistent with the results of Kuorwel et al. [22], whereby a decrease in the TS of thermoplastic starch films was observed by the addition of $3.76 \%$ thymol or $3.49 \%$ carvacrol. Similarly, Bof et al. [23] reported that the TS of starch/chitosan films decreased from 18.4 to $7.9 \mathrm{MPa}$ by the addition of grapefruit seed extract, and it was suggested that the extract interfered with the interactions of the film components. Silva-Weiss et al. [24] also demonstrated that the TS of chitosan/corn starch films containing murta leaf extract 
decreased because of structural discontinuity and irregularity caused by the extract. Sago starch films containing betel leaves extract also showed similar results [25].

Regarding WVP, higher values were observed in ABS films containing CNE compared with that in films without CNE. These results are probably due to the weakened films by the incorporation of CNE, resulting in easy transfer of water molecules. Similarly, Assis et al. [18] demonstrated that the WVP of starch films was increased by the incorporation of $\beta$-carotene, which affected the diffusion of water vapor. Luchese et al. [26] also reported that the WVP of starch films containing blueberry pomace was increased because of decreased intermolecular interactions and increased mobility of the film components.

Table 1. Physical properties of adzuki bean starch (ABS) films containing various amounts of cocoa nibs extract (CNE).

\begin{tabular}{ccccc}
\hline CNE (\%) & Thickness (mm) & Tensile Strength (MPa) & $\begin{array}{c}\text { Elongation at } \\
\text { Break (\%) }\end{array}$ & $\begin{array}{c}\text { Water Vapor Permeability } \\
\mathbf{( 1 0}^{-\mathbf{9}} \mathbf{g} / \mathbf{m ~ s ~ P a )}\end{array}$ \\
\hline 0 & $0.053 \pm 0.002^{\mathrm{d}}$ & $30.59 \pm 2.21^{\mathrm{a}}$ & $10.11 \pm 2.30^{\mathrm{d}}$ & $2.11 \pm 0.12^{\mathrm{b}}$ \\
0.3 & $0.058 \pm 0.001^{\mathrm{c}}$ & $27.74 \pm 0.98^{\mathrm{b}}$ & $13.81 \pm 0.90^{\mathrm{c}}$ & $2.42 \pm 0.27^{\mathrm{ab}}$ \\
0.7 & $0.062 \pm 0.001^{\mathrm{b}}$ & $25.50 \pm 1.12^{\mathrm{c}}$ & $24.51 \pm 2.51^{\mathrm{b}}$ & $2.55 \pm 0.30^{\mathrm{ab}}$ \\
1 & $0.066 \pm 0.003^{\mathrm{a}}$ & $18.58 \pm 1.60^{\mathrm{d}}$ & $27.80 \pm 2.46^{\mathrm{a}}$ & $2.81 \pm 0.49^{\mathrm{a}}$ \\
\hline
\end{tabular}

Mean \pm SD. ${ }^{\text {a-d }}$ Any means in the same column followed by different letters are significantly $(p<0.05)$ different by Duncan's multiple range test.

\subsection{Color Measurement}

With the addition of CNE to the ABS films, the $L^{*}$ value decreased whereas $a *, b *$, and $\Delta E$ increased (Table 2), indicating that the ABS film without CNE was highly transparent and colorless, whereas the films containing CNE had a slight red color. These results could be attributed to the natural pigment in CNE, which has a reddish color. In addition, with increasing amounts of $\mathrm{CNE}$, a decrease in $L^{*}$ was observed, suggesting that the amount of CNE was associated with the lightness of the films. Cheng et al. [27] reported that films with low $L^{*}$ value could be prepared with the addition of phenolic compounds, and these films could protect packaged foods that are sensitive to light. Similarly, Talón et al. [28] reported that the incorporation of polyphenols from thyme extract into chitosan/starch films reduced the $L^{*}$ value of the films. Additionally, the opacity of ABS films containing CNE was higher than that of films without CNE. In general, the incorporation of active materials into the films increases the opacity of the films $[18,23]$.

Table 2. Optical properties of ABS films containing various amounts of cocoa nibs extract.

\begin{tabular}{cccccc}
\hline CNE (\%) & $\boldsymbol{L}^{*}$ & $\boldsymbol{a}^{*}$ & $\boldsymbol{b}^{*}$ & $\boldsymbol{\Delta}$ & Opacity (A/mm) \\
\hline 0 & $95.93 \pm 0.50^{\mathrm{a}}$ & $-0.22 \pm 0.03^{\mathrm{d}}$ & $2.31 \pm 0.26^{\mathrm{d}}$ & - & $1.34 \pm 0.10^{\mathrm{d}}$ \\
0.3 & $88.69 \pm 0.13^{\mathrm{b}}$ & $1.94 \pm 0.07^{\mathrm{c}}$ & $14.48 \pm 0.12^{\mathrm{c}}$ & $14.32 \pm 0.06^{\mathrm{c}}$ & $2.02 \pm 0.11^{\mathrm{c}}$ \\
0.7 & $75.99 \pm 0.18^{\mathrm{c}}$ & $6.94 \pm 0.08^{\mathrm{b}}$ & $30.92 \pm 0.26^{\mathrm{b}}$ & $35.66 \pm 0.28^{\mathrm{b}}$ & $4.84 \pm 0.03^{\mathrm{b}}$ \\
1 & $69.49 \pm 0.86^{\mathrm{d}}$ & $10.97 \pm 0.50^{\mathrm{a}}$ & $36.62 \pm 0.45^{\mathrm{a}}$ & $44.91 \pm 0.87^{\mathrm{a}}$ & $5.63 \pm 0.08^{\mathrm{a}}$ \\
\hline
\end{tabular}

Mean \pm SD. ${ }^{\text {a-d }}$ Any means in the same column followed by different letters are significantly $(p<0.05)$ different by Duncan's multiple range test.

Similarly, Luchese et al. [26] demonstrated a decrease in lightness and an increase in the opacity of starch films containing blueberry pomace. Overall, the incorporation of CNE caused changes in the optical properties of the ABS films, especially the decrease in $L^{*}$ and increase in opacity. Therefore, the developed ABS films in this study are applicable to the packaging of fatty foods. 


\subsection{UV-Visible Light Transmittance}

Figure 2 shows the UV-visible transmittance of the ABS films, where differences between the control (ABS film without $\mathrm{CNE}$ ) and ABS films containing CNE were observed. In particular, the control film had high transmittance, whereas the ABS films containing CNE had relatively low transmittance (200 to $800 \mathrm{~nm}$ ). Thus, the incorporation of CNE caused high absorption below $400 \mathrm{~nm}$, corresponding to UV light, which could cause lipid oxidation in foods. In particular, the ABS films with $1 \% \mathrm{CNE}$ prevented almost all UV transmission, indicating that the films could protect packaged foods against UV light [1]. Moreover, in the visible light range of 400 to $800 \mathrm{~nm}$, the ABS films containing CNE had lower transmittance than that of the control film. Therefore, the ABS films containing CNE could be utilized as effective UV-shielding films. Similar results have been reported in starch films containing natural extracts $[25,26]$.

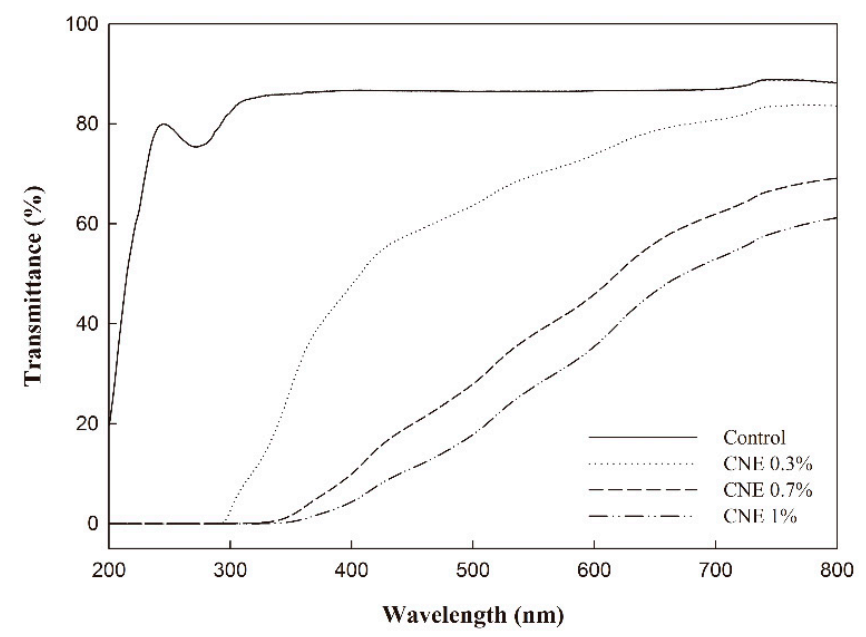

Figure 2. UV-visible light transmittance of adzuki bean starch films.

\subsection{TPC Analysis}

The TPC of the ABS films containing CNE was determined (Figure 3). As expected, the TPC increased as the amount of CNE increased. In particular, the TPC of the ABS film with $1 \%$ CNE was $31.78 \mathrm{mg}$ gallic acid/g film, which is relatively higher than previously reported values [29]. According to a report by Shojaee-Aliabadi et al. [30], the TPC of k-carrageenan films with 3\% Satureja hortensis essential oil was $20.56 \mathrm{mg}$ gallic acid/g film. In general, the TPC is related to antioxidant activity. Effective free radical scavenging capacity of natural extracts is mainly derived from phenolic constituents in their composition. Therefore, the antioxidant activity of the ABS films containing CNE is closely related with the TPC of the films.

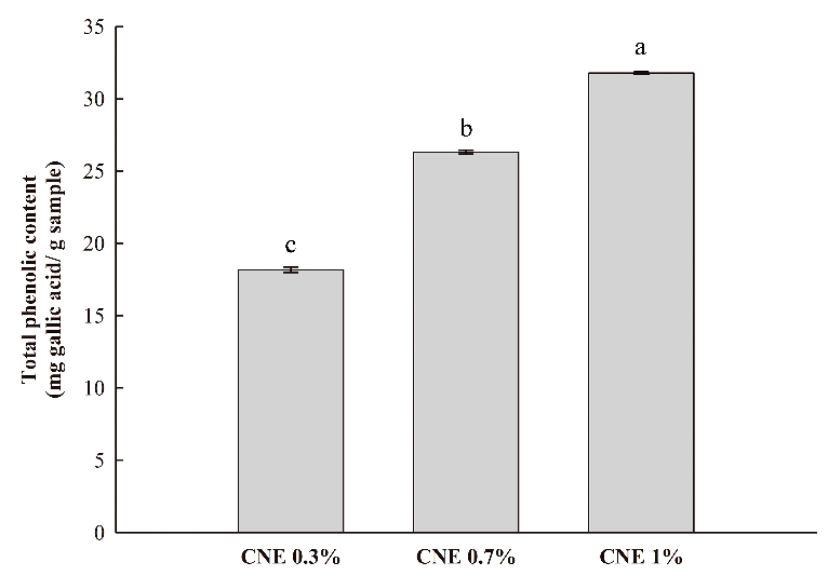

Figure 3. Total phenolic contents of adzuki bean starch films containing cocoa nibs extract. 


\subsection{Antioxidant Activity}

As presented in Table 3, the ABS film without CNE did not exhibit antioxidant property, whereas the antioxidant property of the films containing CNE was proportional to the amount of added CNE. Similarly, Yang et al. [15] demonstrated that pure foxtail millet starch films had no antioxidant activity, but films with clove leaf oil showed increased ABTS and DPPH scavenging activities with increasing amounts of clove leaf oil. In this study, the ABS film containing 1\% CNE showed the highest antioxidant activity, and the ABTS and DPPH scavenging activities were $100 \%$ and $94.9 \%$, respectively. These results indicate that ABS films containing CNE have good antioxidant activity compared with that of antioxidant biodegradable films in other reports. Antioxidants can be released by molecular diffusion from the films to the packaged product. This phenomenon occurs within free volume of the polymer amorphous region. In addition, the stability of antioxidant activity of the films containing natural antioxidants is generally prolonged until 30 days. According to the report by Wu et al. [31], antioxidant capacity of the biodegradable films containing green tea extract showed stability during storage for 30 days. Therefore, ABS films containing CNE could prevent lipid oxidation of packaged foods and be applied as a potential active packaging material.

Table 3. Antioxidant activities of ABS films containing various amounts of cocoa nibs extract.

\begin{tabular}{ccc}
\hline CNE (\%) & ABTS Radical Scavenging (\%) & DPPH Radical Scavenging (\%) \\
\hline 0 & - & - \\
0.3 & $97.70 \pm 0.86^{\mathrm{b}}$ & $66.13 \pm 0.21^{\mathrm{c}}$ \\
0.7 & $99.72 \pm 0.24^{\mathrm{a}}$ & $94.22 \pm 0.40^{\mathrm{b}}$ \\
1 & $100.00 \pm 0.00^{\mathrm{a}}$ & $94.88 \pm 0.05^{\mathrm{a}}$ \\
\hline
\end{tabular}

Means \pm SD. ${ }^{\text {a-c }}$ Any means in the same column followed by different letters are significantly $(p<0.05)$ different by Duncan's multiple range test.

\subsection{ATR-FTIR Analysis}

The ATR-FTIR analysis was used to confirm the incorporation of CNE into the ABS films and examine the possible interactions between CNE and ABS in the films. The ATR-FTIR spectra of ABS, CNE, ABS films, and ABS films containing CNE are presented in Figure 4. The spectrum of ABS shows typical bands at $3300 \mathrm{~cm}^{-1}$ (OH stretching), $2930 \mathrm{~cm}^{-1}$ (CH stretching), and $1657 \mathrm{~cm}^{-1}$ (CO stretching) $[6,7,23,26]$. In contrast, CNE exhibited a peak at $1615 \mathrm{~cm}^{-1}$ (aromatic ring stretching), which was attributed to the phenolic constituents present in CNE. This peak was also observed in the spectrum of blueberry powder containing large amounts of polyphenols [26]. Additionally, at around $1720 \mathrm{~cm}^{-1}$, another peak appeared in the CNE spectrum, which was associated with the presence of $\mathrm{C}=\mathrm{O}$ groups [26]. Meanwhile, the spectra of the ABS films were similar because of their similar compositions. As the amount of $\mathrm{CNE}$ increased, the absorbance at $3300 \mathrm{~cm}^{-1}(\mathrm{OH}$ stretching) was shifted to $3150 \mathrm{~cm}^{-1}$, suggesting changes in hydrogen bonds and intermolecular distance in the composite films [6]. In addition, in the spectra of ABS films containing CNE, slight modifications were observed in the range of 1500 to $1700 \mathrm{~cm}^{-1}$, representing interactions between the starch chains and $\mathrm{CNE}[6,23]$. Furthermore, the peak related to the $\mathrm{CH}_{3}$ rocking bands of ABS films was shifted from $862 \mathrm{~cm}^{-1}$ to higher wavenumbers with increasing CNE content, indicating the presence of chemical interactions between the compounds of CNE and ABS [6]. According to a report by Bof et al. [23], plant extracts containing polyphenolic compounds in the composition had a corresponding peak at $890 \mathrm{~cm}^{-1}$. Because CNE also showed a peak at $890 \mathrm{~cm}^{-1}$, this peak of the ABS films containing CNE became stronger with increasing CNE content and caused a shift of the band from $862 \mathrm{~cm}^{-1}$. In contrast, the absorbance at $1155 \mathrm{~cm}^{-1}$, which was assigned to $\mathrm{C}-\mathrm{O}-\mathrm{C}$ in glycosidic linkage, was similar regardless of the sample, suggesting that there was no change in the glycosidic chain length by the incorporation of CNE [7]. Overall, it should be noted that interactions occurred between ABS and $\mathrm{CNE}$ in the ABS films containing CNE, and these interactions altered the ATR-FTIR spectra. 


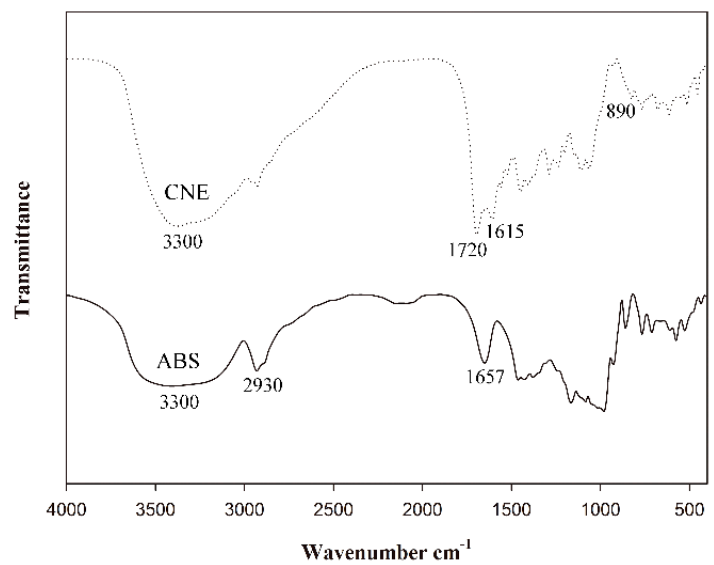

(a)

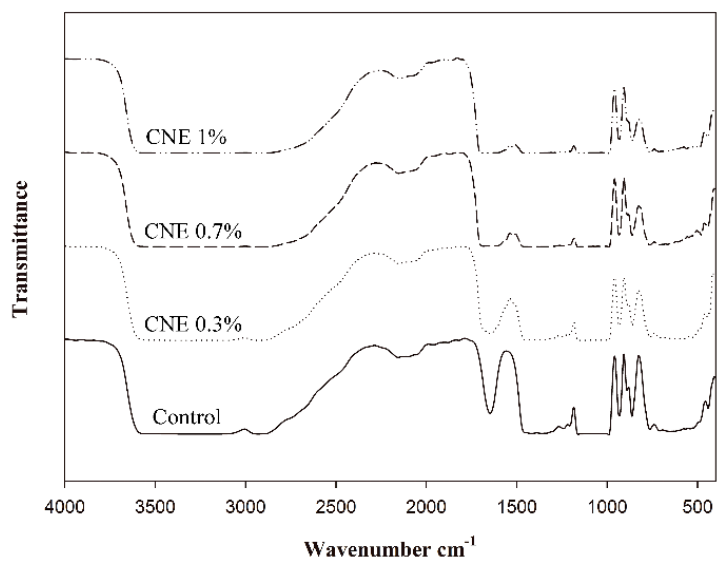

(b)

Figure 4. The attenuated total reflectance-Fourier transformation infrared (ATR-FTIR) spectra. (a) The components; (b) Adzuki bean starch films containing cocoa nibs extract.

\subsection{DSC}

DSC was carried out to analyze the thermal properties of the ABS films (Figure 5a, Table 4). Overall, the DSC results of the ABS films were similar to those reported in other studies [22,26]. In particular, the ABS films showed a broad endothermic peak $\left(30\right.$ to $\left.140^{\circ} \mathrm{C}\right)$ regardless of the sample. The melting temperature $\left(T_{\mathrm{m}}\right)$ of the ABS film $\left(71.97^{\circ} \mathrm{C}\right)$ was slightly lower than that of cassava starch films, which was $80^{\circ} \mathrm{C}$ as reported by Jaramillo et al. [7]. Additionally, the $T_{\mathrm{m}}$ of the ABS films increased with increasing amounts of $\mathrm{CNE}$, possibly because of the higher melting temperature of CNE than that of ABS. Similar results were reported for starch films with blueberry pomace [26] and thermoplastic starch films containing 3.76\% thymol or 3.49\% carvacrol [22]. In terms of enthalpy $(\Delta H)$, the ABS film without CNE had the highest value, suggesting that the addition of CNE decreased thermal energy to dissociate the films. These findings indicate that the thermal stability of the ABS films decreased with the addition of CNE because it increased polymer mobility, resulting in weakening of the film structure, as observed in the physical properties and FTIR of the films.

Table 4. Thermal properties of ABS films containing various amounts of cocoa nibs extract.

\begin{tabular}{ccc}
\hline CNE (\%) & $\boldsymbol{T}_{\mathbf{m}}\left({ }^{\circ} \mathrm{C}\right)$ & $\boldsymbol{\Delta} \boldsymbol{H}(\mathrm{J} / \mathrm{g})$ \\
\hline 0 & 71.97 & 199.51 \\
0.3 & 87.69 & 129.52 \\
0.7 & 96.81 & 146.50 \\
1 & 102.29 & 110.48 \\
\hline
\end{tabular}

According to a report by Kuorwel et al. [22], the addition of active materials into the films could interfere with the association of polymer chains, causing a decrease in film crystallinity. Similarly, the $\Delta H$ of cassava starch films decreased because of changes in intramolecular interactions by the addition of polyphenol-rich compounds [7].

\subsection{TGA}

Figure $5 \mathrm{~b}$ shows the thermal degradation of the ABS films assessed by TGA. In the present study, three typical weight loss stages were observed as reported in the literature [32]. The first stage (50 to $150{ }^{\circ} \mathrm{C}$ ) was associated with water loss in the ABS films. The second stage was attributed to the decomposition of plasticizers added in the film-forming solution $\left(150\right.$ to $\left.220^{\circ} \mathrm{C}\right)$. The third stage was detected in the range of 220 to $350^{\circ} \mathrm{C}$, corresponding to the degradation of ABS. In the third stage, a shift in degradation temperature was observed, suggesting that the ABS film without CNE was thermally stable compared with the films containing CNE. This decrease was reflected in the decrease 
in TS by the incorporation of CNE in the films, which was mainly due to the structural change in the film network. These findings are consistent with the DSC results, where the addition of CNE decreased the thermal stability of the films. Regarding this phenomenon, there have been many similar reports [33]. In addition, the final weights of ABS, ABS- $0.3 \%$ CNE, ABS- $0.7 \%$ CNE, and ABS- $1 \%$ CNE films were $15.02 \%, 20.21 \%, 23.25 \%$, and $25.71 \%$ of the original weight, respectively.

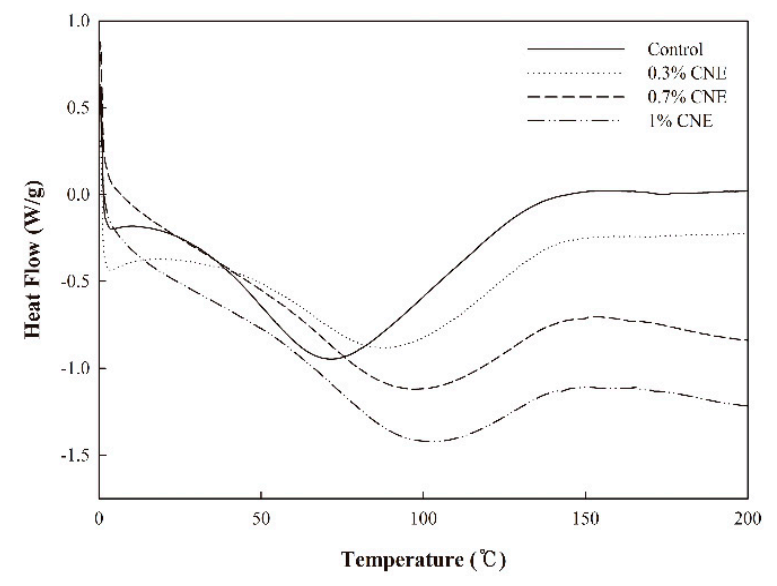

(a)

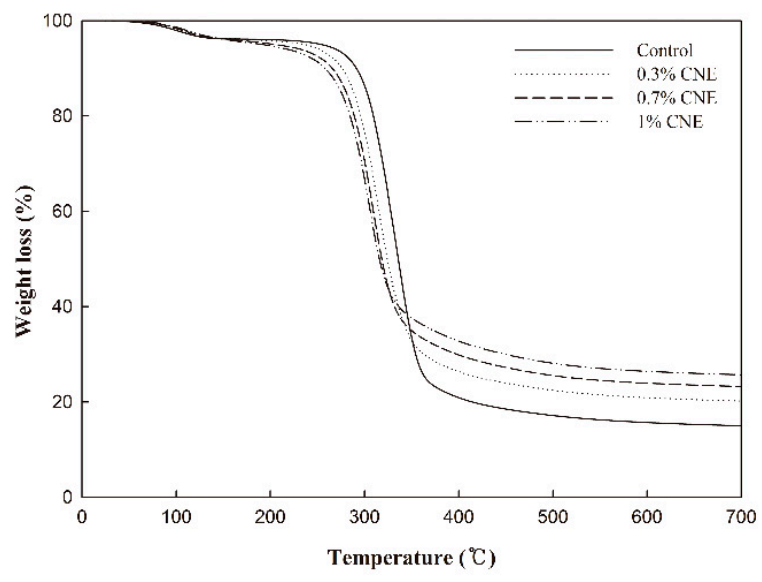

(b)

Figure 5. Thermal properties of adzuki bean starch films containing cocoa nibs extract. (a) Differential scanning calorimetry (DSC); (b) Thermogravimetric analysis (TGA).

\subsection{Biodegradability Test}

To determine the biodegradability of the ABS films, the weight loss of the films buried in vegetable compost was measured for 28 days (Table 5). All films showed changes in weight after 4 days, indicating the beginning of degradation. With the incorporation of CNE, the weight loss of the ABS films increased, and all films were almost completely decomposed after 4 weeks. This phenomenon could be attributed to the moisture and enzymatic activity of microorganisms in the soil [33]. Similar to these results, Xiong et al. [34] demonstrated that the complete decomposition of starch films occurred after 100 days. Torres et al. [35] also reported that the weight loss of starch films buried in soil increased to $99.35 \%$ after one month of storage. It should be noted that the biodegradability of the ABS films was improved by the addition of CNE to the films. This improvement could be explained as CNE contained certain compounds with low molecular weight, which could degrade before ABS. Another explanation is that film biodegradability can be associated with the water solubility of the films. High water solubility leads to fast polymer disintegration during biodegradation [18]. In this study, the ABS films showed an average solubility of $32 \%$ and the solubility increased with the addition of CNE (Table 6), resulting in the high biodegradability of the ABS films containing CNE.

Table 5. Biodegradability of ABS films containing various amounts of cocoa nibs extract.

\begin{tabular}{cccccc}
\hline \multirow{2}{*}{ CNE (\%) } & \multicolumn{5}{c}{ Weight Loss (\%) } \\
\cline { 2 - 6 } & $\mathbf{4 ~ d ~}$ & $\mathbf{7 ~ d ~}$ & $\mathbf{1 4} \mathbf{~ d}$ & $\mathbf{2 1 ~ d ~}$ & $\mathbf{2 8 ~ d}$ \\
\hline 0 & $22.58 \pm 0.23^{\mathrm{Ec}}$ & $42.27 \pm 1.93^{\mathrm{Dc}}$ & $58.12 \pm 1.56^{\mathrm{Cc}}$ & $75.52 \pm 2.05^{\mathrm{Bc}}$ & $98.28 \pm 0.52^{\mathrm{Ab}}$ \\
0.3 & $26.75 \pm 1.09^{\mathrm{Eb}}$ & $51.32 \pm 2.11^{\mathrm{Db}}$ & $67.84 \pm 2.50^{\mathrm{Cb}}$ & $93.38 \pm 0.66^{\mathrm{Bb}}$ & $99.26 \pm 0.35^{\mathrm{Aa}}$ \\
0.7 & $28.41 \pm 1.67^{\mathrm{Eb}}$ & $52.14 \pm 2.50^{\mathrm{Dab}}$ & $74.25 \pm 2.66^{\mathrm{Ca}}$ & $96.07 \pm 1.09^{\mathrm{Ba}}$ & $99.57 \pm 0.24^{\mathrm{Aa}}$ \\
1 & $34.41 \pm 0.59^{\mathrm{Ea}}$ & $56.05 \pm 1.98^{\mathrm{Da}}$ & $75.89 \pm 1.28^{\mathrm{Ca}}$ & $97.45 \pm 0.63^{\mathrm{Ba}}$ & $99.76 \pm 0.24^{\mathrm{Aa}}$ \\
\hline
\end{tabular}

Means \pm SD. ${ }^{\text {a-c }}$ Any means in the same column followed by different letters are significantly $(p<0.05)$ different by Duncan's multiple range test. ${ }^{A-E}$ Any means in the same row followed by different letters are significantly $(p<0.05)$ different by Duncan's multiple range test. 
Table 6. Water solubility and moisture content of ABS films containing various amounts of cocoa nibs extract.

\begin{tabular}{ccc}
\hline CNE (\%) & Water Solubility (\%) & Moisture Content (\%) \\
\hline 0 & $32.38 \pm 1.09^{\mathrm{d}}$ & $7.25 \pm 0.33^{\mathrm{b}}$ \\
0.3 & $35.25 \pm 0.41^{\mathrm{c}}$ & $7.90 \pm 0.80^{\mathrm{ab}}$ \\
0.7 & $39.77 \pm 0.52^{\mathrm{b}}$ & $8.37 \pm 0.31^{\mathrm{a}}$ \\
1 & $44.30 \pm 0.54^{\mathrm{a}}$ & $8.43 \pm 0.34^{\mathrm{a}}$
\end{tabular}

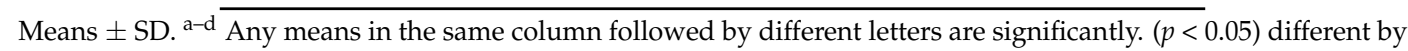
Duncan's multiple range test.

\section{Conclusions}

Biodegradable films based on starch extracted from adzuki bean were developed, and CNE was incorporated to confer antioxidant activity to the films in this study. The incorporation of CNE increased the UV-shielding effect of the films and resulted in good radical scavenging activity against ABTS and DPPH. Moreover, the ABS films containing CNE exhibited higher biodegradability than that of films without CNE. These results suggest that ABS films containing CNE can be applied as a new active packaging material in the food industry.

Author Contributions: S.K. designed and performed the experiments, collected and analyzed the data, and drafted the manuscript; S.-K.B. and E.G. assisted in the experiments; K.B.S. conceived and supervised the study and prepared the final manuscript.

Funding: This research received no external funding.

Conflicts of Interest: The authors declare no conflict of interest.

\section{References}

1. Dick, M.; Costa, T.M.H.; Gomaa, A.; Subirade, M.; de Oliveira Rios, A.; Flôres, S.H. Edible film production from chia seed mucilage: Effect of glycerol concentration on its physicochemical and mechanical properties. Carbohydr. Polym. 2015, 130, 198-205. [CrossRef] [PubMed]

2. Davoodi, M.; Kavoosi, G.; Shakeri, R. Preparation and characterization of potato starch-thymol dispersion and film as potential antioxidant and antibacterial materials. Int. J. Biol. Macromol. 2017, 104, 173-179. [CrossRef] [PubMed]

3. Reddy, C.K.; Luan, F.; Xu, B. Morphology, crystallinity, pasting, thermal and quality characteristics of starches from adzuki bean (Vigna angularis L.) and edible kudzu (Pueraria thomsonii Benth). Int. J. Biol. Macromol. 2017, 105, 354-362. [CrossRef] [PubMed]

4. Sherasia, P.L.; Garg, M.R.; Bhanderi, B.M. Pulses and Their by-Products as Animal Feed; Food and Agriculture Organization of the United Nations (FAO): Rome, Italy, 2018.

5. Hoover, R.; Hughes, T.; Chung, H.J.; Liu, Q. Composition, molecular structure, properties, and modification of pulse starches: A review. Food Res. Int. 2010, 43, 399-413. [CrossRef]

6. Tran, T.N.; Athanassiou, A.; Basit, A.; Bayer, I.S. Starch-based bio-elastomers functionalized with red beetroot natural antioxidant. Food Chem. 2017, 216, 324-333. [CrossRef] [PubMed]

7. Jaramillo, C.M.; Gutiérrez, T.J.; Goyanes, S.; Bernal, C.; Famá, L. Biodegradability and plasticizing effect of yerba mate extract on cassava starch edible films. Carbohydr. Polym. 2016, 151, 150-159. [CrossRef] [PubMed]

8. Lozano-Navarro, J.I.; Díaz-Zavala, N.P.; Velasco-Santos, C.; Martínez-Hernández, A.L.; Tijerina-Ramos, B.I.; García-Hernández, M.; Rivera-Armenta, J.L.; Páramo-García, U.; Reyes-de la Torre, A.I. Antimicrobial, optical and mechanical properties of chitosan-starch films with natural extracts. Int. J. Mol. Sci. 2017, 18, 997. [CrossRef] [PubMed]

9. Yang, H.J.; Lee, J.H.; Won, M.; Song, K.B. Antioxidant activities of distiller dried grains with solubles as protein films containing tea extracts and their application in the packaging of pork meat. Food Chem. 2016, 196, 174-179. [CrossRef] [PubMed] 
10. Schinella, G.; Mosca, S.; Cienfuegos-Jovellanos, E.; Pasamar, M.Á.; Muguerza, B.; Ramón, D.; Ríos, J.L. Antioxidant properties of polyphenol-rich cocoa products industrially processed. Food Res. Int. 2010, 43, 1614-1623. [CrossRef]

11. Ortega, N.; Romero, M.P.; Macià, A.; Reguant, J.; Anglès, N.; Morelló, J.R.; Motilva, M.J. Obtention and characterization of phenolic extracts from different cocoa sources. J. Agric. Food Chem. 2008, 56, 9621-9627. [CrossRef] [PubMed]

12. Mazor Jolić, S.; Radojčić Redovniković, I.; Marković, K.; Ivanec Šipušić, Đ.; Delonga, K. Changes of phenolic compounds and antioxidant capacity in cocoa beans processing. Int. J. Food Sci. Technol. 2011, 46, 1793-1800. [CrossRef]

13. Kulling, S.E.; Rawel, H.M. Chokeberry (Aronia melanocarpa)-A review on the characteristic components and potential health effects. Planta Med. 2008, 74, 1625-1634. [CrossRef] [PubMed]

14. Lu, S.; Cik, T.T.; Lii, C.Y.; Lai, P.; Chen, H.H. Effect of amylose content on structure, texture and $\alpha$-amylase reactivity of cooked rice. LWT-Food Sci. Technol. 2013, 54, 224-228. [CrossRef]

15. Yang, S.Y.; Cao, L.; Kim, H.; Beak, S.E.; Song, K.B. Utilization of foxtail millet starch film incorporated with clove leaf oil for the packaging of Queso Blanco cheese as a model food. Starch-Stärke 2018, 70, 1700171. [CrossRef]

16. Cao, T.L.; Yang, S.Y.; Song, K.B. Development of burdock root inulin/chitosan blend films containing oregano and thyme essential oils. Int. J. Mol. Sci. 2018, 19, 131.

17. Adilah, Z.M.; Jamilah, B.; Hanani, Z.N. Functional and antioxidant properties of protein-based films incorporated with mango kernel extract for active packaging. Food Hydrocoll. 2018, 74, 207-218. [CrossRef]

18. Assis, R.Q.; Pagno, C.H.; Costa, T.M.H.; Flôres, S.H.; Rios, A.D.O. Synthesis of biodegradable films based on cassava starch containing free and nanoencapsulated $\beta$-carotene. Packag. Technol. Sci. 2018, 31, 157-166. [CrossRef]

19. Nogueira, G.F.; Fakhouri, F.M.; de Oliveira, R.A. Extraction and characterization of arrowroot (Maranta arundinaceae L.) starch and its application in edible films. Carbohydr. Polym. 2018, 186, 64-72. [CrossRef] [PubMed]

20. Fu, L.; Zhu, J.; Zhang, S.; Li, X.; Zhang, B.; Pu, H.; Li, L.; Wang, Q. Hierarchical structure and thermal behavior of hydrophobic starch-based films with different amylose contents. Carbohydr. Polym. 2018, 181, 528-535. [CrossRef] [PubMed]

21. Tomas-Barberán, F.A.; Cienfuegos-Jovellanos, E.; Marín, A.; Muguerza, B.; Gil-Izquierdo, A.; Cerdá, B.; Zafrilla, P.; Morillas, J.; Ibarra, A.; Pasamar, M.A. A new process to develop a cocoa powder with higher flavonoid monomer content and enhanced bioavailability in healthy humans. J. Agric. Food Chem. 2007, 55, 3926-3935. [CrossRef] [PubMed]

22. Kuorwel, K.K.; Cran, M.J.; Sonneveld, K.; Miltz, J.; Bigger, S.W. Physico-mechanical properties of starch-based films containing naturally derived antimicrobial agents. Packag. Technol. Sci. 2014, 27, 149-159. [CrossRef]

23. Bof, M.J.; Jiménez, A.; Locaso, D.E.; Garcia, M.A.; Chiralt, A. Grapefruit seed extract and lemon essential oil as active agents in corn starch-chitosan blend films. Food Bioprocess Tech. 2016, 9, 2033-2045. [CrossRef]

24. Silva-Weiss, A.; Bifani, V.; Ihl, M.; Sobral, P.J.A.; Gómez-Guillén, M.C. Structural properties of films and rheology of film-forming solutions based on chitosan and chitosan-starch blend enriched with murta leaf extract. Food Hydrocoll. 2013, 31, 458-466. [CrossRef]

25. Nouri, L.; Nafchi, A.M. Antibacterial, mechanical, and barrier properties of sago starch film incorporated with betel leaves extract. Int. J. Biol. Macromol. 2014, 66, 254-259. [CrossRef] [PubMed]

26. Luchese, C.L.; Garrido, T.; Spada, J.C.; Tessaro, I.C.; de la Caba, K. Development and characterization of cassava starch films incorporated with blueberry pomace. Int. J. Biol. Macromol. 2018, 106, 834-839. [CrossRef] [PubMed]

27. Cheng, S.Y.; Wang, B.J.; Weng, Y.M. Antioxidant and antimicrobial edible zein/chitosan composite films fabricated by incorporation of phenolic compounds and dicarboxylic acids. LWT-Food Sci. Technol. 2015, 63, 115-121. [CrossRef]

28. Talón, E.; Trifkovic, K.T.; Nedovic, V.A.; Bugarski, B.M.; Vargas, M.; Chiralt, A.; González-Martínez, C. Antioxidant edible films based on chitosan and starch containing polyphenols from thyme extracts. Carbohydr. Polym. 2017, 157, 1153-1161. [CrossRef] [PubMed]

29. Abdollahi, M.; Rezaei, M.; Farzi, G. A novel active bionanocomposite film incorporating rosemary essential oil and nanoclay into chitosan. J. Food Eng. 2012, 111, 343-350. [CrossRef] 
30. Shojaee-Aliabadi, S.; Hosseini, H.; Mohammadifar, M.A.; Mohammadi, A.; Ghasemlou, M.; Ojagh, S.M.; Hosseini, S.M.; Khaksar, R. Characterization of antioxidant-antimicrobial k-carrageenan films containing Satureja hortensis essential oil. Int. J. Biol. Macromol. 2013, 52, 116-124. [CrossRef] [PubMed]

31. Wu, J.; Chen, S.; Ge, S.; Miao, J.; Li, J.; Zhang, Q. Preparation, properties and antioxidant activity of an active film from silver carp (Hypophthalmichthys molitrix) skin gelatin incorporated with green tea extract. Food Hydrocoll. 2013, 32, 42-51. [CrossRef]

32. Gutiérrez, T.J.; Morales, N.J.; Pérez, E.; Tapia, M.S.; Famá, L. Physico-chemical properties of edible films derived from native and phosphated cush-cush yam and cassava starches. Food Packag. Shelf Life 2015, 3, 1-8. [CrossRef]

33. Cerruti, P.; Santagata, G.; d'Ayala, G.G.; Ambrogi, V.; Carfagna, C.; Malinconico, M.; Persico, P. Effect of a natural polyphenolic extract on the properties of a biodegradable starch-based polymer. Polym. Degrad. Stab. 2011, 96, 839-846. [CrossRef]

34. Xiong, H.; Tang, S.; Tang, H.; Zou, P. The structure and properties of a starch-based biodegradable film. Carbohydr. Polym. 2008, 71, 263-268. [CrossRef]

35. Torres, F.G.; Troncoso, O.P.; Torres, C.; Díaz, D.A.; Amaya, E. Biodegradability and mechanical properties of starch films from Andean crops. Int. J. Biol. Macromol. 2011, 48, 603-606. [CrossRef] [PubMed]

(C) 2018 by the authors. Licensee MDPI, Basel, Switzerland. This article is an open access article distributed under the terms and conditions of the Creative Commons Attribution (CC BY) license (http:/ / creativecommons.org/licenses/by/4.0/). 